\title{
Case Study of Ground Penetrating Radar for Geological Prediction in Qiyueshan Tunnel
}

\author{
Chenglong Zhao, Shucai Li, Jing Wu, Zhenhao Xu ${ }^{*}$, Yanhuan Zhang and Lun Zhou \\ Geotechnical and Structural Engineering Research Center, Shandong University, Ji'nan 250061, Shandong, China \\ ${ }^{*}$ Corresponding author
}

\begin{abstract}
Ground Penetrating Radar(GPR) is a high-frequency electromagnetic pulse technology, which is widely used in geological exploration. Within a short distance, the changes of formation in front of the tunnel face can be detected with high accuracy. It has a higher ability to identify broken fault zone, and its reliability and stability ofdetection results are high. As a result, Ground penetrating radar method has important significance in guiding tunnel construction. As for Liwan- highway Qiyueshan tunnel, the advanced geological prediction is carried out based on Ground penetrating radar method. The specific characteristics of GPR waves are analyzed and summarized. A number of geological disasters are forecasted successfully. The purpose is to illustrate the superiority of ground penetrating radar in the short advanced geological prediction of karst tunnels, which has some reference for similar karst tunnel projects in future.
\end{abstract}

Keywords- ground penetrating radar; Qiyueshan tunnel; advanced geological prediction; karst tunnels

\section{INTRODUCTION}

Due to unknown geological condition ahead in tunnel construction, undesirable geological factors are often encountered, such as fault, crushed zone, karst cave and underground river. These geological factors not only influence tunnel excavation speed, but also cause severe engineering accidents such as collapse, debris flow, water burst and other destructive geological disasters. As it is difficult for engineering geological survey result before tunnel construction to meet construction requirements in accuracy and reliability, if changes of lithological structure ahead of the working face can be known accurately in advance in the process of tunnel excavation, excavation speed can be arranged reasonably, construction scheme can be modified and protective measures can be arranged in time, thus avoiding the occurrence of dangerous cases ${ }^{[1-2]}$. In recent years, with the constant progress of science and technology, GPR technology has been widely applied to advanced geological prediction of tunnel] ${ }^{[3-7]}$. Radar images obtained by repeated detection of the working face of tunnel with GPR have a high similarity. With small influence of the outside world, accurate prediction result and sensitivity to abnormal geological reactions such as karst cave, underground river and fault fracture zone at $20 \sim 30 \mathrm{~m}$, it can make up for insensitivity of TSP to small karst caves to a certain extent[8-12].

With advanced geological prediction of Qiyueshan Tunnel on Lichuan-Wanzhou Expressway as research background, this paper studies features of influence of GPR on undesirable geologic bodies and the change rule of its wave form and discusses the effectiveness of short-term advanced geological prediction of GPR in tunnel. It has great significance for guiding tunnel construction.

\section{BASIC PRINCIPLES OF AdVANCED GEOLOGICAL PREDICTION OF GPR SELECTING A TEMPLATE}

Figure 1 shows basic principles of the work of GPR. GPR transmits electromagnetic wave to the interior of tested surface through transmitting antenna. The receiving antenna receives reflected waves from different medium faces in the interior of tested surface. The path, intensity and waveform of electromagnetic wave change when it is transmitted through different mediums. The structure of medium can be inferred according to two way travel time, amplitude and waveform data of electromagnetic wave received. GPR can predict lithological changes of the stratum ahead of the tested surface and has a high ability of recognizing fault zone, especially water zone and crushed zone ${ }^{[13-15]}$. For fractured rock mass, such phenomena as event disorder of reflected wave and disorder of reflecting interface and amplitude decays very rapidly. Water-rich rock mass is mainly manifested as strong reflection band on radar image; meanwhile, the dominant frequency of reflected wave decreases significantly and the phase reverses. The pulse period of reflected wave in waterrich rock mass increases greatly and energy decays rapidly after it passes through water-rich rock mass.

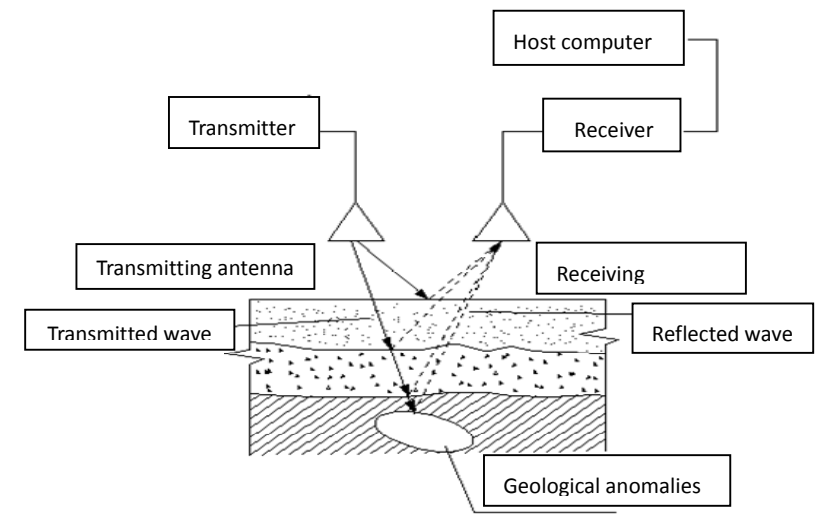

FIGURE 1.
BASIC PRINCIPLES OF GPR 


\section{Advanced GeOlogical PREDiction of QIYUEshan TUNNEL}

\section{A. Project Profile}

Qiyueshan Tunnel on Lichuan-Wanzhou Expressway is located between Nanping Village and Moudao Town, Lichuan City, Hubei Province, China. The area where the tunnel is located belongs to grand fold belt of Sichuan, Hubei, Hunan and Guizhou. The area through which the tunnel passes mainly includes limestone, shale and coal bed. Fault has developed around the core of anticline. It is a development area of karst. In the scope of the area where the tunnel is located, two faults have developed, i.e. Qiyueshan fault and Deshengchang fault. Both faults are narrow in the tunnel body and basically vertical to the path. Karst has developed in the fault zone. There is a high possibility for the existence of large karst cave.

\section{B. Measuring Line Layout of GPR}

GPR was used to conduct short-distance GPR detection on the right hole bottom board YK19+116 YK19+131 at the entrance of Qiyueshan Tunnel with antenna frequency $100 \mathrm{MHz}$ and sample collection point 512. Figure 2 shows the schematic diagram of measuring line layout.

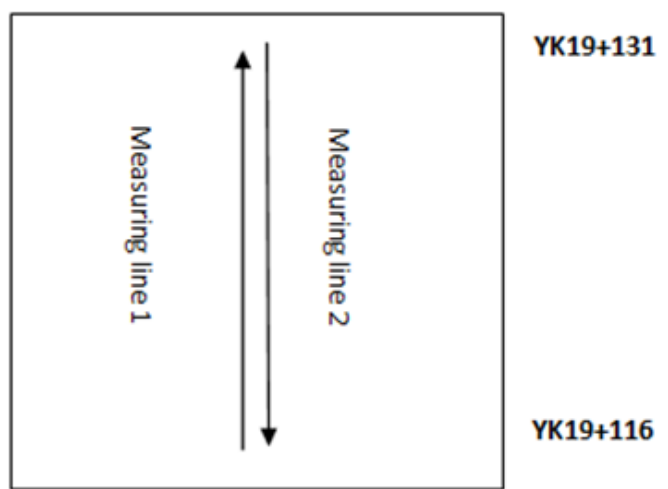

FIGURE II.

SCHEMATIC DIAGRAM OF RADAR MEASURING LINE

\section{Analysis on GPR Detection Result}

The depth of this GPR detection was 20ms and the range of measuring bottom board was YK19+116 YK19+131. Figure 3 Figure 6 show radar images of measuring lines 1 and 2.

Figure 3 Figure 6 show strong signal reaction and low main reflective frequency at $11 \sim 20 \mathrm{~m}$ underground from mileage pile numbers YK19+116 to YK19+131, showing rich water or serious folder mud of this rock mass. According to on- site geological situation and relevant geological data, this rock mass is broken; karst fissures have developed and a lot of fissure karst water or weak folder mud exists. From mileage pile numbers YK19+125 to YK19+129, there is a strong signal reaction at $4 \sim 12 \mathrm{~m}$ underground. According to on-site geological situation and relevant geological data, surrounding rocks are broken and there are argillaceous substances. From mileage pile numbers YK19+128 to YK19+131, there is an abnormal signal reaction at 2 10m underground. According to on-site geological situation and relevant geological data, karst cave exists in this place, which is filled with argillaceous substances.

\section{Verification of Actual Excavation Result}

In the tunnel construction process of YK19+116 YK19+131 sections, it was found that the rock mass was broken and karst fissures have developed and fissure karst water was encountered. In the tunnel construction process of YK19+125 YK19+129 sections, surrounding rock crushed zone with argillaceous substances was found. In the construction process of YK19+128 YK19+131 sections, a karst cave was found at YK19+128.5, which was filled with argillaceous substances. All this verifies the effectiveness and accuracy of advanced geological prediction of GPR.

\section{CONCLUSION}

Advanced geological prediction is conducted on karst tunnel with GPR. Its prediction result and actual tunnel excavation result are in good agreement. The following conclusions are made:

(a) GPR can predict undesirable geologic bodies ahead in the short term accurately and timely and guide safety tunnel construction. It has small influence on the construction. The detection result has high reliability and stability.

(b) It has a good rate of detection and recognition of the development situation of intermediary-intense weathered fractured rock mass and existing karst cave, fissure and underground water, and good prediction effect in the stage of entering for construction and shallow burying construction. Appropriate measures can be taken to protect self-stability of surrounding rocks to the greatest extent.

(c) With advanced prediction through GPR, its construction speed can be over $20 \%$ faster than traditional construction method. It can save over 8\% excavation costs. Currently, GPR method has become an indispensable advanced geological prediction method in tunnel construction. 
(1970)

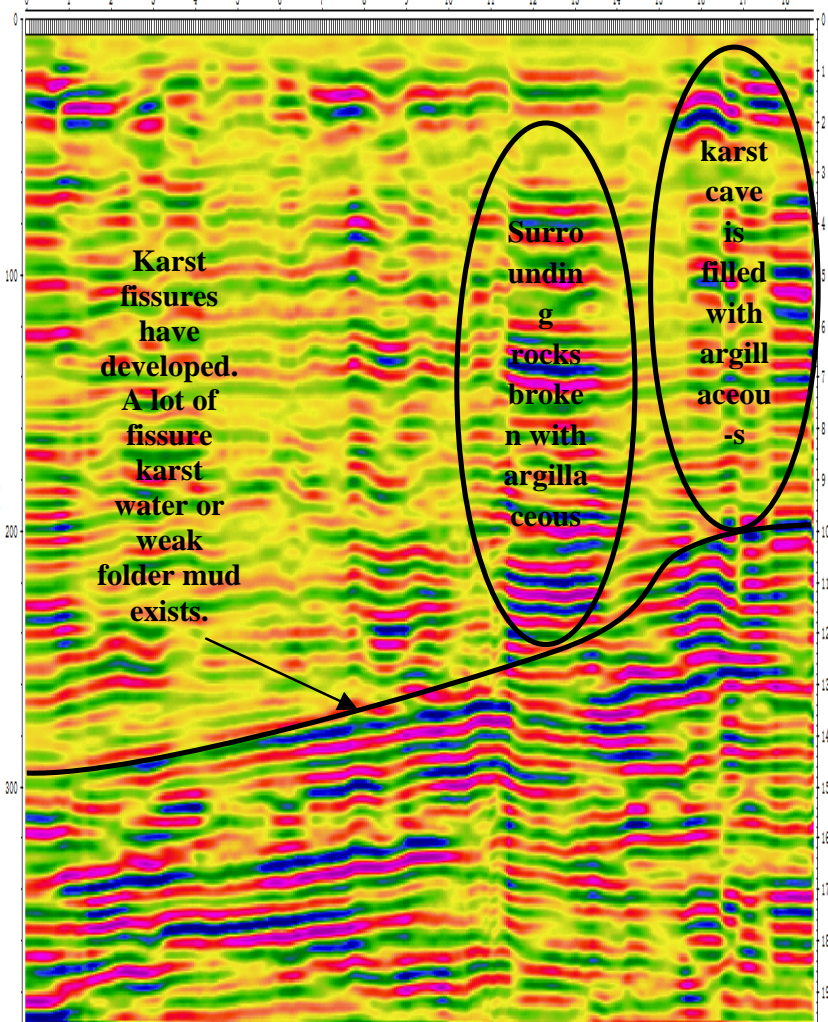

FIGURE III.

GPR WAVE FORM IMAGE OF MEASURING LINE 1

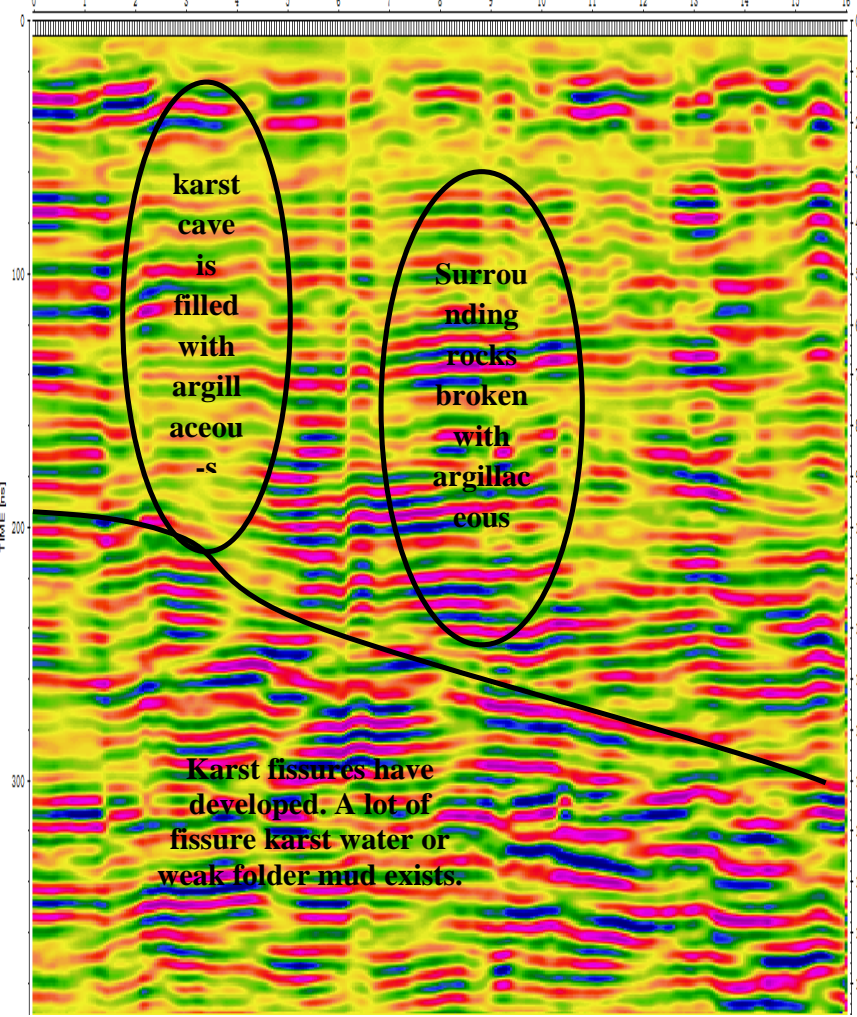

FIGURE V.

GPR WAVE FORM IMAGE OF MEASURING LINE 2
DISWEEVIET

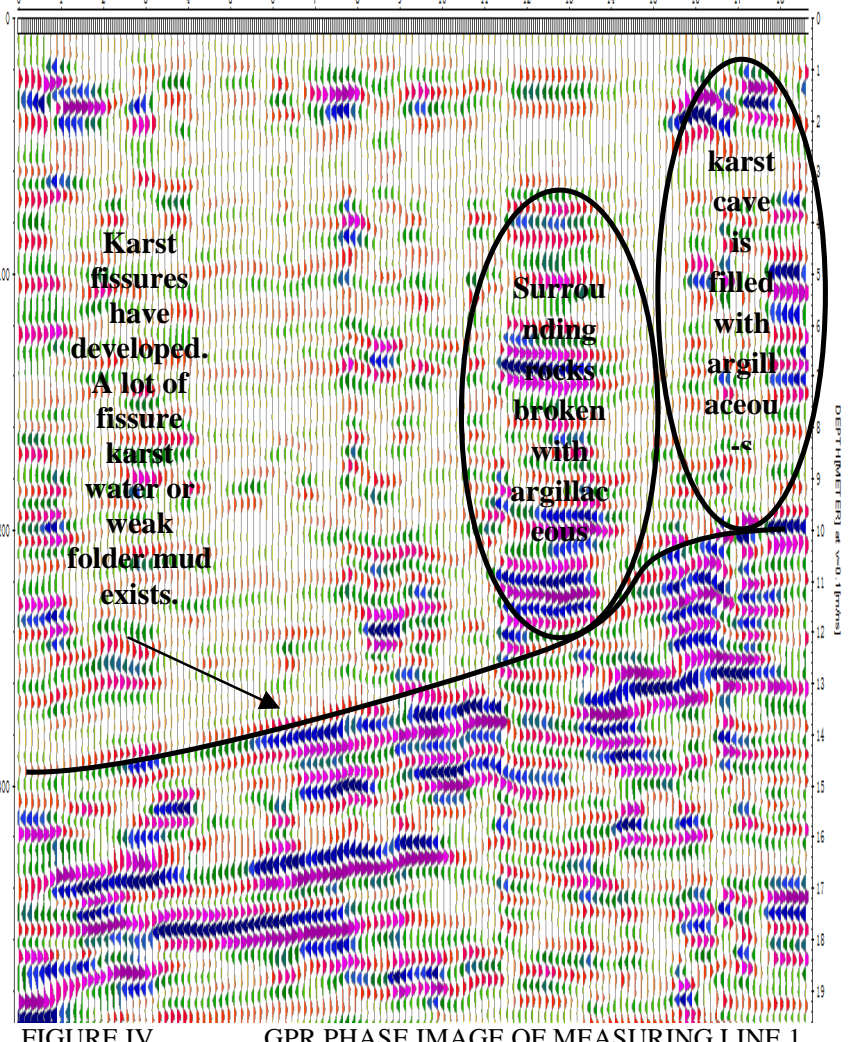

DISANEVIEEP

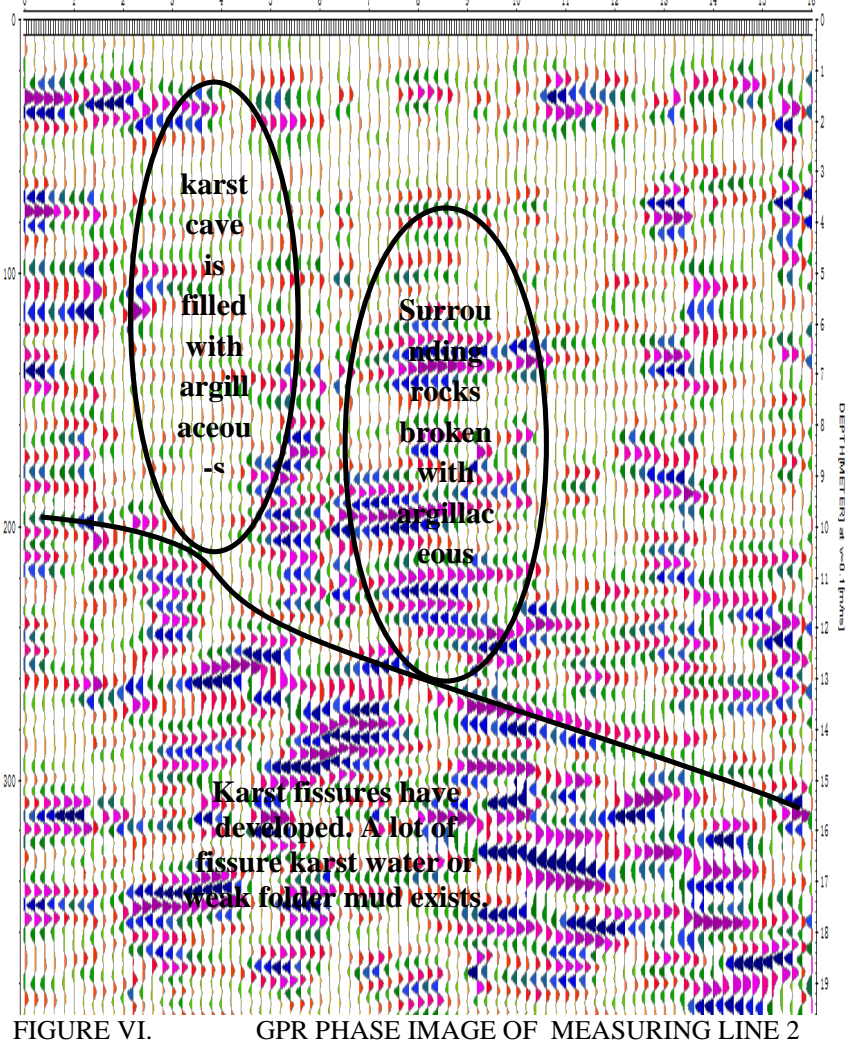




\section{ACKNOWLEDGMENTS}

We would like to acknowledge the financial support from the National Basic Research Program of China (973 Program, No.: 2013CB036000) and the promotive research fund for excellent young and middle-aged scientists of Shandong Province(No.: 2014GN028) and the China Postdoctoral Science Foundation (No.: 2014M551908).

\section{REFERENCES}

[1] J. L. Fangi,S. Ying,J. Jia, “Application of Ground Penetrating Radar in geological forecast for highway tunnels”,CarsologicaSinica, vol. 24, No.2, 2005, pp.160-163.

[2] Y. Gao,Q. S. Zhang, "Application of Ground Penetrating Radar to geological forecast in karst tunnel”, Journal of Shandong University (Engineering Science), vol. 39, No.4, 2009, pp. 82-86.

[3] X. M. Wu,X. H. Yue,Y. B. Yang, “.Application of Ground Penetrating Radar on the advanced prediction in a highway tunnel construction”,Soil Eng.and Foundation. 2012, 26(1): 74-76.

[4] SH. Dong. "The application of Ground Penetrating Radar in karst tunnel advanced prediction”,Gansu Science and Technology , vol. 30, No.2, 2014, pp.32-34.

[5] J. Wu,H. H. Mao,S. Ying. “Application of ground probing radar to short-term geological forecast for tunnel construction”, Rock and Soil Mechanics, vol. 24, No.10, 2003.

[6] H. Y. Wang. "Comprehensive advance geology prediction adopted in Yuanliangshantunnel”, Modern Tunnelling Technology, vol. 41, No.3, 2004, pp. 55-61.

[7] ZH. Bai. “Application of Ground Penetrating Radar in geology forecast for tunnel”, Wu Han: Wuhan University of Technology,2006.

[8] Q. S. Zhang, SH. C. Li, K. G. Sun, et a1. "Analysis and present state of advance geological forecast technology of highway tunnel”, Chinese Journal of Underground Space and Engineering, vol. 4, No.4,2008, pp.640-644.

[9] T. B. Li, L. B. Meng, J. Zhu, et a1. "Comprehensive analysis method for advanced forecast of geology in tunnels”, Chinese Journal of Rock Mechanics and Engineering, vol.28, No.12, 2009, pp.2429-2436.

[10] B. K. Gao, Z. Q. Zhu. "Application of TSP system in geological advanced prediction of tunnel”,West China Exploration Engineering, No.1,2008,pp.139-141.

[11] D. X. Li. "Development and application of Ground Penetrating Radar”,Bei Jing: Geological Publishing House,1994.

[12] J. Wu, H. H. Mao, S. Ying, et a1. "Application of ground probing radar to short-term geological forecast for tunnel construction”, Rock and Soil Mechanics, vol. 24(Supp.),2003,pp.154-157.

[13] B. Liu, SH. C. Li, SH. CH. Li, et a1. "Study of application of complex signal analysis to predicting karstfractured ground water with Ground Penetrating Radar”, vol. 30, No.7, Rock and Soil Mechanics, 2009, pp.2191-2196 